Tol, J., Swinkels, I.C., Bakker, D.H. de, Seidell, J., Veenhof, C. Dietetic treatment lowers body mass index in overweight patients: an observational study in primary health care. Journal of

\begin{tabular}{l|l} 
Postprint Version & 1.0 \\
\hline Journal website & http://onlinelibrary.wiley.com/doi/10.1111/jhn.12175/abstract \\
\hline Pubmed link & http://www.ncbi.nlm.nih.gov/pubmed/24205956 \\
\hline DOI & $10.1111 /$ jhn.12175
\end{tabular}

This is a NIVEL certified Post Print, more info at http://www.nivel.eu

\title{
Dietetic treatment lowers body mass index in overweight patients: An observational study in primary health care
}

\author{
JACQUELINE TOL ${ }^{1,2}$, ILSE C. SWINKELS ${ }^{1}$, DinNy H. DE BAKKER ${ }^{1,3}$, JAAP SEIDELL ${ }^{4}$, CINDY \\ VEENHOF $^{1}$ \\ ${ }^{1}$ Organization: NIVEL (the Netherlands Institute for Health Services Research). \\ Address: P.O. box 1568, 3500 BN Utrecht, the Netherlands \\ ${ }^{2}$ Corresponding Author. \\ Telephone number: +31 302729622 \\ E-mail address: J.Tol@nivel.nl \\ ${ }^{3}$ Organization: TRANZO (Tilburg University, Scientific Centre for Transformation in Care \\ and Welfare). Address: P.O. box 90153, 5000 LE Tilburg, the Netherlands \\ ${ }^{4}$ Organization: VU University of Amsterdam. Address: De Boelelaan 1085, $1081 \mathrm{HV}$ \\ Amsterdam, the Netherlands
}

\section{ABSTRACT}

Background: Greater insight into the effectiveness of usual dietetic care will contribute to the ongoing development of dietetic services. The present study examined the change in body mass index (BMI) in overweight patients following dietetic treatment in primary care, the sources of variability and factors associated with BMI change.

Methods: This population-based observational study was based on data from a Dutch registration network of dietitians in primary health care. Data were derived from electronic medical records concerning 3,960 overweight adult patients (BMI $\geq 25)$ who received usual care from 32 registered dietitians between 2006 and 2012. Multilevel linear regression analyses were conducted.

Results: Patients' BMI significantly $(\mathrm{p}<0.001)$ decreased by $0.94 \mathrm{~kg} / \mathrm{m}^{2}$ on average during treatment. An additional reduction of $0.8 \mathrm{~kg} / \mathrm{m}^{2}$ was observed in patients treated for longer than six months. BMI decreased by $0.06 \mathrm{~kg} / \mathrm{m}^{2}$ for each additional unit in initial BMI above 31.6. Most (97\%) variability in BMI change was attributed to patients and $3 \%$ to dietitians. Part of the variance between patients (11\%) and dietitians (30\%) was explained by patient sociodemographic characteristics, nutrition-related health aspects, initial body weight and treatment duration.

Conclusions: Dietetic treatment in primary care lowers BMI in overweight patients. Patients' change in BMI was rather similar between dietitians. Greater BMI reductions were observed in those with a high initial BMI and those treated 
Tol, J., Swinkels, I.C., Bakker, D.H. de, Seidell, J., Veenhof, C. Dietetic treatment lowers body mass index in overweight patients: an observational study in primary health care. Journal of Human Nutrition and Dietetics: 2014, 27(5), 426-433

for at least six months. Future research is necessary to study long-term effects of weight loss after treatment by primary health care dietitians, especially since many patients drop out of treatment prematurely.

\section{INTRODUCTION}

Obesity is a worldwide epidemic (World Health Organization, 2012a). Obesity rates are among the highest in the United States. In 2009-2010, 33.3\% of US adults were overweight and 35.9\% were obese (National Center for Health Statistics, 2012). Obesity rates vary between European countries (Branca et al., 2007). In the Netherlands, $36 \%$ of the adult population was overweight and almost $12 \%$ was obese in 2011 (Statistics Netherlands, 2012a). Overweight and obesity are major risk factors for noncommunicable diseases, such as cardiovascular diseases and diabetes (World Health Organization, 2012b). As a consequence, the total healthcare costs attributed to overweight and obesity are high (Wang et al., 2008, 2011). For these reasons it is important that treatment results in positive health outcomes. Evidence suggests that $5-10 \%$ of weight loss is associated with meaningful improvements in health-related risk factors, such as serum lipids, glucose tolerance and blood pressure (Mertens \& Van Gaal, 2000; Yu-Poth et al., 1999).

Many studies have investigated the effect of diets or dietary counselling on weight loss (Avenell et al., 2004; Dansinger et al., 2007). However, little research has been conducted to examine the influence of the dietitian on weight loss. Some randomized studies have shown that patients who receive dietary counselling from a dietitian achieve significantly larger weight loss when compared to either other providers (Croft et al., 1986; Delahanty et al., 2001; Diaz et al., 2010; Nybacka et al., 2011; Willaing et al., 2004), or other methods (Raatz et al., 2008). A limitation of these studies is that the results are based on the effectiveness of a single dietitian, while there might be differences between dietitians which could lead to different weight loss outcomes (Lok et al., 2010). Another possible weakness of experimental intervention studies on weight loss is that they might represent a maximum treatment effect because of the optimized conditions and participants' high levels of motivation (Glasgow et al., 2003). Therefore, more studies in 'real life' situations are recommended, such as in a primary health care setting, to observe the outcome of dietetic treatment and to investigate whether there are differences between dietitians. Furthermore, research is needed to study the factors associated with weight loss in dietetic practice. Although many studies have identified factors associated with weight loss, such as self-monitoring, self-efficacy, social support, or motivation, (Elfhag \& Rossner, 2005) some of the previously defined factors associated with weight loss may be specifically related to healthy people and to the type of weight loss strategy employed.

This study was conducted to determine the empirically observed change in BMI in overweight patients following dietetic treatment in primary health care. Further objectives were to explore sources of variability and factors associated with BMI change, such as patient socio-demographic characteristics, nutrition-related health aspects, initial body weight and treatment duration. Accordingly, this study examines the effect of dietetic treatment in primary care on: 1) overweight patients' mean change in body mass index; 2) the sources of variability in overweight patients' change in BMI; 3) factors associated with overweight patients' change in BMI. 
Tol, J., Swinkels, I.C., Bakker, D.H. de, Seidell, J., Veenhof, C. Dietetic treatment lowers body mass index in overweight patients: an observational study in primary health care. Journal of Human Nutrition and Dietetics: 2014, 27(5), 426-433

\section{METHODS}

\section{Registration network: sampling}

Data were derived from the electronic medical records of dietitians who participated in the National Information Service for Allied Health Care (LiPZ). LiPZ is a Dutch computerized registration network for allied health care professionals (Swinkels, 2008). It includes about 30 registered dietitians working in private practices in primary health care. According to the Dutch Dietetic Association, in January 2011, about $55 \%$ of all Dutch dietitians worked in a primary healthcare setting, such as a private practice or home care. The network has been collecting data on dietetic health care on a continuous basis since 2006.

For the LiPZ study, dietitians were recruited in 2005, through advertisements on the website of a specific software program used by dietitians (EVRY; Ensemble, Zoetermeer, the Netherlands). In addition, dietitians were recruited via a previous questionnaire-based study conducted among a representative sample of 500 primary care dietitians for the purpose of measuring their interest in participating in LiPZ. In order to be eligible for participation, the dietitians had to be working in a private practice in the Netherlands and use the Evry software program for the administration of patient, treatment, and reimbursement information. No exclusion criteria were applied. The dietitians were representative of the Dutch population of dietitians in primary care with respect to practice region and level of urbanicity (Leemrijse et al., 2008; Tol, et al., 2012). For participating in LiPZ, the dietitians received financial remuneration, points for accreditation in the quality register for dietitians, and benchmark data updates on an annual basis.

\section{Registration network: data collection}

The participating dietitians registered data on all their patients in the Evry software program, frequently used for patient administration by Dutch dietitians in private practice. The software program was designed to record relevant information on patients' treatments, as well as particulars related to reimbursement (i.e. date and time of consultations). An additional module was installed in the software program specifically for LiPZ. Dietitians were instructed to register information in this module at the start and at the end of patients' treatment. Patient data collection was based on extractions from this software program. Data were collected at consultation level and were submitted on a monthly basis. The data were entered into the database after standardized quality control checks on missing or inconsistent data. The participants received an overview of the missing or inconsistent data and were asked to complete or adjust the data accordingly. Corrected data were included in the nextmonth submitted datafile, and were adjusted in the database accordingly.

For the current study, ethical approval was not required in the Netherlands, since the patients were receiving customary care from dietitians, and no experimental interventions were involved. (For more information about patients' dietetic treatment, see Table 1) The Dutch Data Protection Authority was informed about the LiPZ study. Pursuant to the Personal Data Protection Act, data were collected anonymously, patients were informed about the LiPZ study by leaflets and posters in the waiting rooms of the practices, and patients could opt not to participate in the LiPZ study. 
Tol, J., Swinkels, I.C., Bakker, D.H. de, Seidell, J., Veenhof, C. Dietetic treatment lowers body mass index in overweight patients: an observational study in primary health care. Journal of Human Nutrition and Dietetics: 2014, 27(5), 426-433

\section{[TABLE 1]}

\section{Study outcome and independent variables}

The outcome of this study (dependent variable) was patients' change in Body Mass Index (BMI at the end of treatment minus BMI at the start of treatment). Participating dietitians registered patients' body weight and height in the software program. BMI was electronically calculated by dividing a patient's body weight in kilograms by his or her height in meters squared and was extracted from the software program.

The independent variables (see Table 2) were measured at the start of treatment. Dietitians recorded data on the patient's age, gender, level of education and whether the patient had dietetic healthcare in the past five years. In addition, data were registered on communication problems (e.g. language barriers), psychological problems (including binge-eating disorder), intellectual disability or cardiovascular risk factors. A cardiovascular risk factor was defined as being overweight and having diabetes, hypertension or hypercholesterolemia. Not having a cardiovascular risk factor was defined as being overweight with or without another diagnosis. Medical diagnoses were registered by the dietitian and were based on medical information obtained during the nutrition care process. A maximum of four diagnoses per patient were registered, based on a specially developed reference guide for dietitians (The Dutch Association of Dietetics, 2004). Further independent variables used in this study were BMI at treatment start and the duration of a treatment episode. The duration of treatment was based on the difference between a patient's first and last consultation date. An algorithm was created to define an episode of treatment. The treatment was considered as closed when the dietitian entered a reason for ending treatment in the software program, or when the time between the last consultation date and the last date on which information was supplied to LiPZ was longer than six months. LiPZ data showed that in only one percent of the patients did a gap of at least six months occur between two successive consultations.

\section{[TABLE 2 ]}

\section{Study sample}

The clustered convenience sample of this longitudinal observational study was based on data from 8,294 overweight ( $\mathrm{BMI} \geq 25 \mathrm{~kg} / \mathrm{m}^{2}$ ) adult ( $>18$ years) patients who were treated by 32 dietitians between 1 January 2006 and 1 January 2012. Included were data from dietitians who participated for at least six months in LiPZ and registered sufficient data on BMI, i.e. had complete data on BMI for at least $10 \%$ of their patients. Overall, 9 dietitians (who treated 511 patients) did not meet the inclusion criteria and 2 patients were excluded due to extreme outcome values.

\section{Statistical analyses}

For the purpose of this study, data were aggregated to patients' episodes of treatment. Descriptive analyses were performed in STATA (version 12.1, 2012, STATACorp, College Station Texas). The research questions were analysed with multilevel linear regression analyses in MLwiN (Version 2.25, 2012, Centre for Multilevel Modelling, University of Bristol). Multilevel analyses were conducted to account for the clustered two-level structure of the data, viz., dietitians, and patients' treatment 
Tol, J., Swinkels, I.C., Bakker, D.H. de, Seidell, J., Veenhof, C. Dietetic treatment lowers body mass index in overweight patients: an observational study in primary health care. Journal of Human Nutrition and Dietetics: 2014, 27(5), 426-433

episodes. Five models were developed to explore the sources of variability in change in BMI, namely: model 0 (intercept-only model); model 1 (adjusted for age, gender, educational level, and previous dietetic treatment); model 2 (adjusted for the variables of model 1 and communication problems, psychological problems, intellectual disability and cardiovascular risk factors); model 3 (adjusted for the variables of model 2 and BMI at treatment start); model 4 (adjusted for the variables of model 3 and treatment duration). All continuous variables were centered at the mean, and tested for linearity. Total variance estimates at patient and dietitian level were calculated for all models. Furthermore, regression coefficients, standard errors and p-values were calculated for the variables of model 4 , to test the factors that were associated with a change in body mass index. The significance level was set at a pvalue of $\leq 0.05$. The analyses were performed on patients with complete data.

\section{RESULTS}

\section{Sample size}

Included in this study were 8,294 overweight adult patients of whom 6,237 had complete data on independent variables. The percentage of missing data on the dependent variable varied widely between dietitians, from $4.1 \%$ to $83.3 \%(n=32)$. The results are shown for patients with complete data of both dependent and independent variables $(n=3,960)$. The patients with complete data were significantly different with respect to age, intellectual disability, cardiovascular risk factors, and mean BMI at treatment start compared to patients with missing data on BMI at the end of treatment (Table 2).

\section{Mean change in body mass index}

At treatment start $43.5 \%$ of patients were overweight and $56.5 \%$ were obese. At the end of dietetic treatment $6.2 \%$ had a healthy BMI $<25$, $48.3 \%$ were overweight and $45.5 \%$ were obese. During dietetic treatment patients' BMI significantly $(\mathrm{p}<0.001)$ decreased by $0.94 \mathrm{~kg} / \mathrm{m} 2$ on average, adjusted for patient socio-demographic characteristics, nutrition-related health aspects, initial body weight and treatment duration (model 4).

\section{Sources of variability in change in body mass index}

Adjusted for the variables of model 4, the average reduction in BMI varied between dietitians from $-1.41 \mathrm{~kg} / \mathrm{m} 2$ to $-0.62 \mathrm{~kg} / \mathrm{m} 2$ ( $\mathrm{p}<0.001$ ) (Fig. 1). The proportion of the total variance explained in BMI change - the intraclass correlation coefficient (ICC) was 0.974 at the patient level and 0.026 at dietitian level. This means that about $3 \%$ of the variance in BMI change was explained by dietitians. The total variance at patient and dietitian level decreased when more variables were included in the analyses (Table 3). Compared to the intercept-only model, $10.5 \%$ of the variance between patients and $29.8 \%$ of the variance between dietitians was explained by the variables of model $4(\mathrm{p}<0.01)$. Most of the variance in BMI change was explained by treatment duration. 
Tol, J., Swinkels, I.C., Bakker, D.H. de, Seidell, J., Veenhof, C. Dietetic treatment lowers body mass index in overweight patients: an observational study in primary health care. Journal of Human Nutrition and Dietetics: 2014, 27(5), 426-433

\section{[FIGURE 1][TABLE 3 ]}

\section{Factors associated with a change in body mass index}

Overweight patients with cardiovascular risk factors or other diagnoses (e.g. irritable bowel syndrome, gastro-oesophageal reflux or chronic obstructive pulmonary disease) had significantly smaller reductions in BMI compared to patients with overweight alone (Table 4). In addition, significantly smaller BMI reductions were observed in patients with psychological problems compared to those without psychological problems and in patients who were treated previously by a dietitian compared to patients who were not treated previously by a dietitian.

The relationship between treatment duration and change in BMI was not linear. Therefore, treatment duration was categorized into four groups. Reductions of -0.8 $\mathrm{kg} / \mathrm{m}^{2}$ were observed in patients treated longer than six months compared to patients with a treatment duration of less than six months.

Each unit increase in BMI above 31.6 at treatment start was significantly associated with an additional reduction of $0.06 \mathrm{~kg} / \mathrm{m}^{2}$ at treatment end. Further linear multilevel analyses were performed to put this result into perspective. Data were subdivided into three groups of patients, i.e. overweight (BMI 25 - 29.9), obese (BMI 30 - 34.9) and extremely obese (BMI 35+) at treatment start. Adjusted for patient sociodemographic characteristics, nutrition-related health aspects, initial body weight and treatment duration, BMI significantly $(\mathrm{p}<0.001)$ decreased by $0.73 \mathrm{~kg} / \mathrm{m}^{2}$ on average in overweight patients, by $0.90 \mathrm{~kg} / \mathrm{m}^{2}$ in obese patients and by $1.49 \mathrm{~kg} / \mathrm{m}^{2}$ in extremely obese patients (data not shown in Table).

\section{[TABLE 4]}

\section{Discussion}

This is one of the first studies in a primary healthcare setting to observe that treatment given by dietitians results in a significant BMI reduction of $-0.94 \mathrm{~kg} / \mathrm{m}^{2}$ on average. These results are comparable to another study in primary health care, where a reduction of $1.14 \mathrm{~kg} / \mathrm{m}^{2}$ was found (Willaing et al., 2004). Furthermore, the results show that $3 \%$ of the variance in patients' mean BMI change can be attributed to differences between dietitians. This is relatively low compared to other studies in primary health care (Fung et al., 2010). Low proportional variances have often been interpreted as indicating little potential for quality improvement efforts. However, a study by Selby et al. (2011) showed that even low proportional variances can mask clinically important differences across practitioners. Therefore, the absolute amount of variation, expressed in clinically meaningful units, is important in interpreting the results. Since adjusted results for average BMI change in the current study ranged from -1.41 to $-0.62 \mathrm{~kg} / \mathrm{m}^{2}$ between dietitians, many patients do not achieve clinically relevant outcomes of treatment. For example, BMI reductions of 1.41 and $0.62 \mathrm{~kg} / \mathrm{m}^{2}$ are equivalent to reductions of $4.5 \%$ and $2.0 \%$ in weight (based on the average BMI of 31.6 at the start of this study and the average height of $181 \mathrm{~cm}$ in Dutch males and $168 \mathrm{~cm}$ in Dutch females (Statistics Netherlands, 2012a,b). The effects on change in BMI were modest as patients who dropped out of treatment were also included. For example, twelve percent of the patients ended treatment after only one consultation (data not shown). Even though change in BMI was modest, it may still contribute to 
Tol, J., Swinkels, I.C., Bakker, D.H. de, Seidell, J., Veenhof, C. Dietetic treatment lowers body mass index in overweight patients: an observational study in primary health care. Journal of Human Nutrition and Dietetics: 2014, 27(5), 426-433

the improvement of cardiovascular risk factors, (Wing et al., 2011) and possibly to other outcomes valued by the patient, such as perceived quality of life or satisfaction with treatment (Jackson et al., 2005). Therefore, future studies should also focus on patient-centered outcomes of dietetic treatment. Another important issue is whether weight losses are more or less well maintained. More research is necessary to study the long-term effect of weight loss after treatment by primary health care dietitians. Part of the variance in BMI change between patients and between dietitians was explained by the independent variables in the study. Most of the variance in BMI change was explained by treatment duration. There was no linear relationship between treatment duration and BMI reduction. Similar changes in BMI were observed in patients with a treatment duration longer than 12 months, compared to patients with a treatment duration between 6 and 12 months. Possibly, BMI reductions remain quite similar over time because the maintenance phase will help prevent patients from regaining weight after 12 months. This result was inconsistent with a systematic review of dietary counselling interventions for weight loss, showing that almost all trials reported steady weight regain over time during the maintenance phase (Dansinger et al., 2007). Further research is necessary to study the long-term effect of weight loss after treatment by primary health care dietitians, especially since many patients stopped treatment within the first year. High drop-out rates are commonly seen in obesity management. Drop-out may be attributable to having a fulltime job, family problems, unsatisfactory results, or a lack of motivation (Dalle Grave et al., 2006; Inelmen et al., 2005). Overall, more knowledge about predictors of drop-out in dietetic practice may help reduce drop-out and increase the effectiveness of dietetic treatment.

In agreement with previous studies, a higher initial BMI was associated with greater reduction in BMI (Finkler et al., 2012). This may be because energy reduction is easier to implement in heavier individuals who typically have a higher initial energy intake, leading to greater total energy deficit.

Further results of this study showed that patients who were previously treated by a dietitian were associated with smaller reductions in BMI. These patients may have a history of dieting failure, and therefore dietitians focus less on calorie restriction and more on improvements in lifestyle for chronic disease risk reduction (Ikeda et al., 2004). Furthermore, patients with psychological problems were associated with smaller reductions in BMI, as is supported by other research (Elfhag et al., 2005). Patients with cardiovascular risk factors or other co-morbidities were also significantly associated with smaller reductions in BMI. It is possible that these patients use medication that negatively influences weight loss (Dutch Institute for Health Improvement CBO, 2008).

Caution is needed in interpreting our findings on BMI change since there was a relatively high number of patients with missing data. Missing data could be related to the dietitian or to the patient. One possibility is that missing data on BMI change was due to poor registration of end variables by dietitians in general since the percentage of missing data on BMI change ranged from $4.1 \%$ to $83.3 \%$ between dietitians. In addition, missing data on BMI change could be due to no-show of patients with disappointing weight loss results. Sensitivity analyses were performed to estimate the possible influence of disappointing BMI changes for those with incomplete data on the results of the study. Three imputation methods were used for patients with missing data on BMI change. The results for all three sensitivity analyses were 
Tol, J., Swinkels, I.C., Bakker, D.H. de, Seidell, J., Veenhof, C. Dietetic treatment lowers body mass index in overweight patients: an observational study in primary health care. Journal of Human Nutrition and Dietetics: 2014, 27(5), 426-433

essentially the same. Patients' mean change in BMI and the total explained variance in changed BMI between patients and their dietitians could at the most be slightly overestimated. The factors associated with a change in BMI were comparable to complete case analyses, although regression coefficients and standard errors were slightly lower (results not shown).

A strength of this study is that the data were based on actual dietetic treatments of patients in primary health care, because the data were entered by the dietitian in a software program used for regular practice administration and reimbursement. Additionally, data were continuously collected on a large number of patients. Another strength is that additional questions for the study were completed by the dietitian during the consultation or shortly afterwards. Therefore, there is little risk of recall bias.

\section{Conclusion}

Dietetic treatment in primary healthcare lowers BMI in overweight patients. Patients’ change in BMI was rather similar between dietitians. Greater BMI reductions were observed in those with a high initial BMI and those treated for at least six months. Future research is necessary to study the long-term effect on weight loss after treatment by primary health care dietitians, especially since many patients drop out of treatment prematurely.

\section{Acknowledgments}

This research was funded by the Dutch Ministry of Health, Welfare and Sport. There are no conflicts of interest. We would like to thank the study participants for their contribution.

\section{Conflict of interests, source of funding and authorship}

The authors declare that there are no conflicts of interest. This research was funded by the Dutch Ministry of Health, Welfare and Sport. All authors were involved in the conception and design of the study and in the interpretation of data. D.H. de B., C.V., I.C.S. and J.T. were involved with data collection. D.H. de B. obtained funding for the study and J.T. performed data analysis and drafted the paper. All authors critically reviewed the article and have approved the final version submitted for publication.

\section{REFERENCES}

Avenell, A., Brown, T.J., McGee, M.A., Campbell, M.K., Grant, A.M., Broom, J., Jung, R.T., \& Smith, W.C. (2004) What are the long-term benefits of weight reducing diets in adults? A systematic review of randomized controlled trials. J.Am.Diet.Assoc. 17, 317-335.

Branca F, Nikogosian H, Lobstein T. The challenge of obesity in the WHO European Region and the strategies for response. World Health Organization: 2007.

Croft, P.R., Brigg, D., Smith, S., Harrison, C.B., Branthwaite, A., \& Collins, M.F. (1986) How useful is weight reduction in the management of hypertension? J.R.Coll.Gen.Pract. 36, 445-448.

Dalle Grave, R.D., Suppini, A., Calugi, S., and Marchesini, G. (2006) Factors associated with attrition in weight loss programs. Int J Behav Consult Ther. 2, 341-353.

Dansinger, M.L., Tatsioni, A., Wong, J.B., Chung, M., \& Balk, E.M. (2007) Meta-analysis: the effect of dietary counseling for weight loss. Ann.Intern.Med. 147, 41-50. 
Tol, J., Swinkels, I.C., Bakker, D.H. de, Seidell, J., Veenhof, C. Dietetic treatment lowers body mass index in overweight patients: an observational study in primary health care. Journal of Human Nutrition and Dietetics: 2014, 27(5), 426-433

Delahanty, L.M., Sonnenberg, L.M., Hayden, D., \& Nathan, D.M. (2001) Clinical and cost outcomes of medical nutrition therapy for hypercholesterolemia: a controlled trial.

J.Am.Diet.Assoc. 101, 1012-1023.

Diaz, R.G., Esparza-Romero, J., Moya-Camarena, S.Y., Robles-Sardin, A.E., \& Valencia, M.E. (2010) Lifestyle intervention in primary care settings improves obesity parameters among Mexican youth. J.Am.Diet.Assoc. 110, 285-290.

Elfhag, K. \& Rossner, S. (2005) Who succeeds in maintaining weight loss? A conceptual review of factors associated with weight loss maintenance and weight regain. Obes.Rev. 6 , 67-85.

Finkler, E., Heymsfield, S.B., \& St-Onge, M.P. (2012) Rate of Weight Loss Can Be Predicted by Patient Characteristics and Intervention Strategies. J.Acad.Nutr.Diet. 112, 75-80.

Fung, V., Schmittdiel, J.A., Fireman, B., Meer, A., Thomas, S., Smider, N., Hsu, J., \& Selby, J.V. (2010) Meaningful variation in performance: a systematic review. Medical Care. 48, 140-148.

Glasgow, R.E., Lichtenstein, E., \& Marcus, A.C. (2003) Why don't we see more translation of health promotion research to practice? Rethinking the efficacy-to-effectiveness transition. Am.J.Public Health 93, 1261-1267.

Ikeda, J.P., Lyons, P., Schwartzman, F., \& Mitchell, R.A. (2004) Self-reported dieting experiences of women with body mass indexes of 30 or more. J.Am.Diet.Assoc. 104, $972-$ 974.

Inelmen, E.M., Toffanello, E.D., Enzi, G., Gasparini, G., Miotto, F., Sergi, G., \& Busetto, L. (2005) Predictors of drop-out in overweight and obese outpatients. Int J Obes.(Lond) 29, 122-128.

Jackson, J.A., Kinn, S., \& Dalgarno, P. (2005) Patient-centred outcomes in dietary research. J.Am.Diet.Assoc. 18, 83-92.

Dutch Institute for Health Improvement CBO. (2008) Guideline diagnostics and treatment of obesity in adults and children (in Dutch: Richtlijn diagnostiek en behandeling van obesitas bij volwassenen en kinderen). Utrecht: Van Zuiden Communications.

Leemrijse, C. J., Swinkels, I. C. S., Veenhof, C., \& de Bakker, D. (2008) Annual report LiPZ 2006 \& 2007, dietetics occupational group, data collection on dietitians working in private practices in primary health care (in Dutch: Jaarboek LiPZ 2006 \& 2007, beroepsgroep diëtetiek, gegevensverzameling binnen vrijgevestigde praktijken voor diëtetiek). Utrecht: NIVEL.

Lok, K.Y.W., Chan, R.S.M., Sea, M.M.M., \& Woo, J. (2010) Nutritionist's variation in counseling style and the effect on weight change of patients attending a community based lifestyle modification program. Int J Environ Res Public Health. 7, 413-426.

Mertens, I.L. \& Van Gaal, L.F. (2000) Overweight, obesity, and blood pressure: the effects of modest weight reduction. Obes.Res. 8, 270-278.

National Center for Health Statistics (2012). Health, United States, 2011: With Special Feature on Socioeconomic Status and Health. Hyattsville (MD).

Nybacka, A., Carlstrom, K., Stahle, A., Nyren, S., Hellstrom, P.M., \& Hirschberg, A.L. (2011) Randomized comparison of the influence of dietary management and/or physical exercise on ovarian function and metabolic parameters in overweight women with polycystic ovary syndrome. Fertil.Steril. 96, 1508-1513.

Raatz, S.K., Wimmer, J.K., Kwong, C.A., \& Sibley, S.D. (2008) Intensive diet instruction by registered dietitians improves weight-loss success. J.Am.Diet.Assoc. 108, 110-113.

Selby, J.V., Schmittdiel, J.A., Lee, J., Fung, V., Thomas, S., Smider, N., Crosson, F.J., Hsu, J., \& Fireman, B. (2011) Meaningful variation in performance: what does variation in quality tell us about improving quality? Med Care. 48, 133-139.

Statistics Netherlands. (2012a) More people overweight. The Hague: Statistics Netherlands. Available at http://www.cbs.nl/en-GB/menu/themas/gezondheidwelzijn/publicaties/artikelen/archief/2012/2012-3651-wm.htm?Languageswitch=on (updated 4 July 2012) (accessed 1 July 2013).

Statistics Netherlands. (2012b) Dutch population taller and heavier. The Hague: Statistics Netherlands. Available at http://www.cbs.nl/en-GB/menu/themas/gezondheidwelzijn/publicaties/artikelen/archief/2012/2012-3746-wm.htm?Languageswitch=on (updated Dec 2012) (accessed 1 July 2013). 
Tol, J., Swinkels, I.C., Bakker, D.H. de, Seidell, J., Veenhof, C. Dietetic treatment lowers body mass index in overweight patients: an observational study in primary health care. Journal of Human Nutrition and Dietetics: 2014, 27(5), 426-433

Swinkels, I. C. S. (2008) Monitoring physiotherapy using a national registration network. Utrecht: NIVEL.

The Dutch Association of Dietetics. (2004) Doctor's reference guide to dietetics. Houten NVD. Available at http://www.artsenwijzer.info/site/index.php?page=1\&action=\&lg=en (updated 2913) (accessed July 2013).

The Dutch Dietetic Association. (2011) Statistics of the Dutch Dietetic Association. Houten: NVD. Available at http://www.nvdietist.nl/content.asp?kid=10529458 (updated January 1 2012) (accessed January 27 2012).

Tol, J., Swinkels, I.C.S., Bakker, D.B., \& Veenhof, C. (2012) Annual statistics and trends $2008-2010$ dietetics, data collection on dietitians working in private practices in primary health care (in Dutch: Jaarcijfers en trendcijfers 2008 - 2010 dietetiek, gegevensverzameling binnen vrijgevestigde praktijken voor dietetiek). Utrecht: NIVEL.

Wang, Y., Beydoun, M.A., Liang, L., Caballero, B., \& Kumanyika, S.K. (2008) Will all Americans become overweight or obese? estimating the progression and cost of the US obesity epidemic. Obesity.(Silver.Spring) 16, 2323-2330.

Wang, Y.C., McPherson, K., Marsh, T., Gortmaker, S.L., \& Brown, M. (2011) Health and economic burden of the projected obesity trends in the USA and the UK. Lancet. 378, 815825.

Willaing, I., Ladelund, S., Jorgensen, T., Simonsen, T., \& Nielsen, L.M. (2004) Nutritional counselling in primary health care: a randomized comparison of an intervention by general practitioner or dietician. Eur.J.Cardiovasc.Prev.Rehabil. 11, 513-520.

Wing, R.R., Lang, W., Wadden, T.A., Safford, M., Knowler, W.C., Bertoni, A.G., Hill, J.O., Brancati, F.L., Peters, A., \& Wagenknecht, L. (2011) Benefits of modest weight loss in improving cardiovascular risk factors in overweight and obese individuals with type 2 diabetes. Diabetes Care 34, 1481-1486.

World Health Organization. (2012a) Obesity and overweight. Factsheet number 311. WHO. Available at http://www.who.int/mediacentre/factsheets/fs311/en/ (updated March 2013) (accessed July 2013).

World Health Organization. (2012b) Obesity: preventing and managing the global epidemic. Report of a WHO consultation. Geneva: WHO.

Yu-Poth, S., Zhao, G., Etherton, T., Naglak, M., Jonnalagadda, S., \& Kris-Etherton, P.M. (1999) Effects of the National Cholesterol Education Program's Step I and Step II dietary intervention programs on cardiovascular disease risk factors: a meta-analysis.

Am.J.Clin.Nutr. 69, 632-646. 
TABLE 1. INFORMATION ABOUT PATIENTS’ DIETETIC TREATMENT

\section{Dietary advice}

Dutch dietitians work according to the principles of the nutrition care process, which includes nutrition assessment, diagnosis, intervention, and monitoring/evaluation. The current study did not collect information on patients' dietary intake or on dietetic advice. However, Dutch dietitians are expected to give nutritional advice based on the Dutch dietary guidelines. The guidelines advise patients to make food choices that promote health and help prevent disease, using an energy restricted diet of $600 \mathrm{kcal}$ less than the estimated normal intake.

\section{Treatment duration}

Treatment duration varies between patients and between dietitians. In general, the initial visit takes 45 to 60 minutes of direct treatment time. Follow-up visits take 15 to 30 minutes. One-to-one consultations were the most common form of contact. The guidelines recommend treatment for at least one year, followed by a less intensive period of continuous care for weight maintenance.

\section{Treatment reimbursement}

At the time of this study, dietetic treatment was reimbursed by Dutch standardized primary health insurance for up to a maximum of four hours per calendar year. This reimbursement covers direct treatment time, i.e. the total length of the consultation, and indirect treatment time, i.e. the time the dietitian needs to administer and prepare the consultation. 
Tol, J., Swinkels, I.C., Bakker, D.H. de, Seidell, J., Veenhof, C. Dietetic treatment lowers body mass index in overweight patients: an observational study in primary health care. Journal of Human Nutrition and Dietetics: 2014, 27(5), 426-433

Table 2. Socio-demographic, health and treatment characteristics of patients with complete and missing data on BMI at treatment end.

\begin{tabular}{|c|c|c|c|}
\hline & $\begin{array}{l}\text { Complete } \\
\text { data } \\
(n=3960)\end{array}$ & $\begin{array}{l}\text { Missing } \\
\text { BMI } \\
(n=2277)\end{array}$ & P-value \\
\hline Age in years, mean (SD) & $50.1(15.2)$ & $48.7(14.8)$ & $<0.001$ \\
\hline \multicolumn{4}{|l|}{$\operatorname{Sex}(\%)$} \\
\hline Male & 36.2 & 35.2 & 0.444 \\
\hline Female & 63.8 & 64.8 & \\
\hline \multicolumn{4}{|l|}{ Educational level (\%) } \\
\hline Low & 29.0 & 27.1 & 0.210 \\
\hline Medium & 45.7 & 47.6 & \\
\hline High & 25.2 & 25.3 & \\
\hline \multicolumn{4}{|c|}{ Previous dietetic treatment (\%) } \\
\hline No & 79.8 & 79.6 & 0.906 \\
\hline Yes & 20.3 & 20.4 & \\
\hline \multicolumn{4}{|l|}{ Communication problem (\%) } \\
\hline No & 96.7 & 97.0 & 0.514 \\
\hline Yes & 3.3 & 3.0 & \\
\hline \multicolumn{4}{|l|}{ Psychological problem (\%) } \\
\hline No & 92.6 & 91.3 & 0.067 \\
\hline Yes & 7.4 & 8.7 & \\
\hline \multicolumn{4}{|l|}{ Intellectual disability problem (\%) } \\
\hline No & 98.0 & 98.8 & 0.021 \\
\hline Yes & 2.0 & 1.2 & \\
\hline \multicolumn{4}{|l|}{ Cardiovascular risk factor (\%) } \\
\hline No (single diagnosis) & 39.4 & 43.4 & $<0.001$ \\
\hline $\begin{array}{l}\text { No (diagnosis other } \\
\text { than diabetes, } \\
\text { hypertension } \\
\text { or hypercholesterolaemia) }\end{array}$ & 11.1 & 13.2 & \\
\hline $\begin{array}{l}\text { Yes (diabetes, } \\
\text { hypertension } \\
\text { or hypercholesterolaemia) }\end{array}$ & 49.5 & 43.4 & \\
\hline $\begin{array}{l}\text { BMl at treatment start, } \\
\text { mean (SD) }\end{array}$ & $31.5(4.7)$ & $32.3(5.2)$ & $<0.001$ \\
\hline \multicolumn{4}{|l|}{ Treatment duration (\%) } \\
\hline 0-6 months & 62.3 & 63.2 & 0.283 \\
\hline $7-12$ months & 22.8 & 20.9 & \\
\hline $1-1.5$ years & 7.2 & 7.6 & \\
\hline 1.5 years + & 7.7 & 8.4 & \\
\hline
\end{tabular}


Tol, J., Swinkels, I.C., Bakker, D.H. de, Seidell, J., Veenhof, C. Dietetic treatment lowers body mass index in overweight patients: an observational study in primary health care. Journal 0 Human Nutrition and Dietetics: 2014, 27(5), 426-433

Table 3. Proportion of variance explained in multiple regression models on patients BMI change after dietetic treatment $(n=3,960)$

\begin{tabular}{lcc}
\hline & $\begin{array}{l}\text { Dietitian level \% } \\
\text { (variance estimate) }\end{array}$ & $\begin{array}{l}\text { Patient level \% } \\
\text { (variance estimate) }\end{array}$ \\
\hline Intercept only model & $(0.084)$ & $(2.494)$ \\
Model 1: age, sex, educational level, previous dietetic treatment & $-0.0(0.084)$ & $-0.2(2.489)$ \\
Model 2: communication problems, psychological problems, & $-0.0(0.084)$ & $-0.7(2.471)$ \\
intellectual disability, cardiovascular risk factors & $+1.2(0.085)$ & $-3.3(2.389)$ \\
Model 3: body mass index at treatment start & $-30.6(0.059)$ & $-6.3(2.239)$ \\
Model 4: treatment duration & -29.8 & -10.5 \\
\hline Total & \\
\hline
\end{tabular}


Tol, J., Swinkels, I.C., Bakker, D.H. de, Seidell, J., Veenhof, C. Dietetic treatment lowers body mass index in overweight patients: an observational study in primary health care. Journal 0 Human Nutrition and Dietetics: 2014, 27(5), 426-433

Table 4. Factors associated with change in body mass index in 3,960 overweight patients treated by 32 primary health care dietitians. Results from linear multilevel regression-analysis adjusted for socio-demographic characteristics, nutrition-related health aspects, initial body weight and treatment duration.

\begin{tabular}{|c|c|c|c|}
\hline & $\begin{array}{l}\text { Regression } \\
\text { coefficient } \\
\left(\mathrm{kg} \mathrm{m}^{-2}\right)\end{array}$ & $\begin{array}{l}\text { Standard } \\
\text { error }\end{array}$ & $P$-value \\
\hline Age (years) (reference mean) & -0.002 & 0.002 & 0.181 \\
\hline \multicolumn{4}{|l|}{ Sex } \\
\hline \multicolumn{4}{|l|}{ Male (reference) } \\
\hline Female & -0.039 & 0.052 & 0.461 \\
\hline \multicolumn{4}{|l|}{ Educational level } \\
\hline \multicolumn{4}{|l|}{ Low (reference) } \\
\hline Medium & -0.015 & 0.060 & 0.799 \\
\hline High & -0.131 & 0.071 & 0.065 \\
\hline \multicolumn{4}{|l|}{ Previous dietetic treatment } \\
\hline \multicolumn{4}{|l|}{ No (reference) } \\
\hline Yes & 0.251 & 0.062 & $<0.001$ \\
\hline \multicolumn{4}{|l|}{ Communication problems } \\
\hline \multicolumn{4}{|l|}{ No (reference) } \\
\hline Yes & 0.071 & 0.143 & 0.618 \\
\hline \multicolumn{4}{|l|}{ Psychological problems } \\
\hline \multicolumn{4}{|l|}{ No (reference) } \\
\hline Yes & 0.192 & 0.094 & 0.040 \\
\hline \multicolumn{4}{|l|}{ Intellectual disability } \\
\hline \multicolumn{4}{|l|}{ No (reference) } \\
\hline Yes & 0.349 & 0.184 & 0.058 \\
\hline \multicolumn{4}{|l|}{ Cardiovascular risk factor } \\
\hline \multicolumn{4}{|c|}{ No (single diagnosis) (reference) } \\
\hline $\begin{array}{l}\text { No (diagnosis other than } \\
\text { diabetes, hypertension or } \\
\text { hypercholesterolaemia) }\end{array}$ & 0.254 & 0.083 & 0.002 \\
\hline $\begin{array}{l}\text { Yes (diabetes, hypertension } \\
\text { or hypercholesterolaemia) }\end{array}$ & 0.162 & 0.061 & 0.008 \\
\hline $\begin{array}{l}\text { BMI at treatment start } \\
\text { (reference mean) }\end{array}$ & -0.056 & 0.005 & $<0.001$ \\
\hline \multicolumn{4}{|l|}{ Treatment duration } \\
\hline \multicolumn{4}{|l|}{ 0-6 months (reference) } \\
\hline $7-12$ months & -0.835 & 0.059 & $<0.001$ \\
\hline $1-1.5$ years & -0.829 & 0.096 & $<0.001$ \\
\hline 1.5 yearst & -0.862 & 0.095 & $<0.001$ \\
\hline Intercept & -0.935 & 0.092 & $<0.001$ \\
\hline
\end{tabular}


Tol, J., Swinkels, I.C., Bakker, D.H. de, Seidell, J., Veenhof, C. Dietetic treatment lowers body mass index in overweight patients: an observational study in primary health care. Journal 0 Human Nutrition and Dietetics: 2014, 27(5), 426-433

Figure 1. Variation between dietitians in patients' mean BMI change with 95\% confidence interval, adjusted for socio-demographic characteristics, nutritionrelated health aspects, initial body weight and treatment duration $(n=3,960)$.

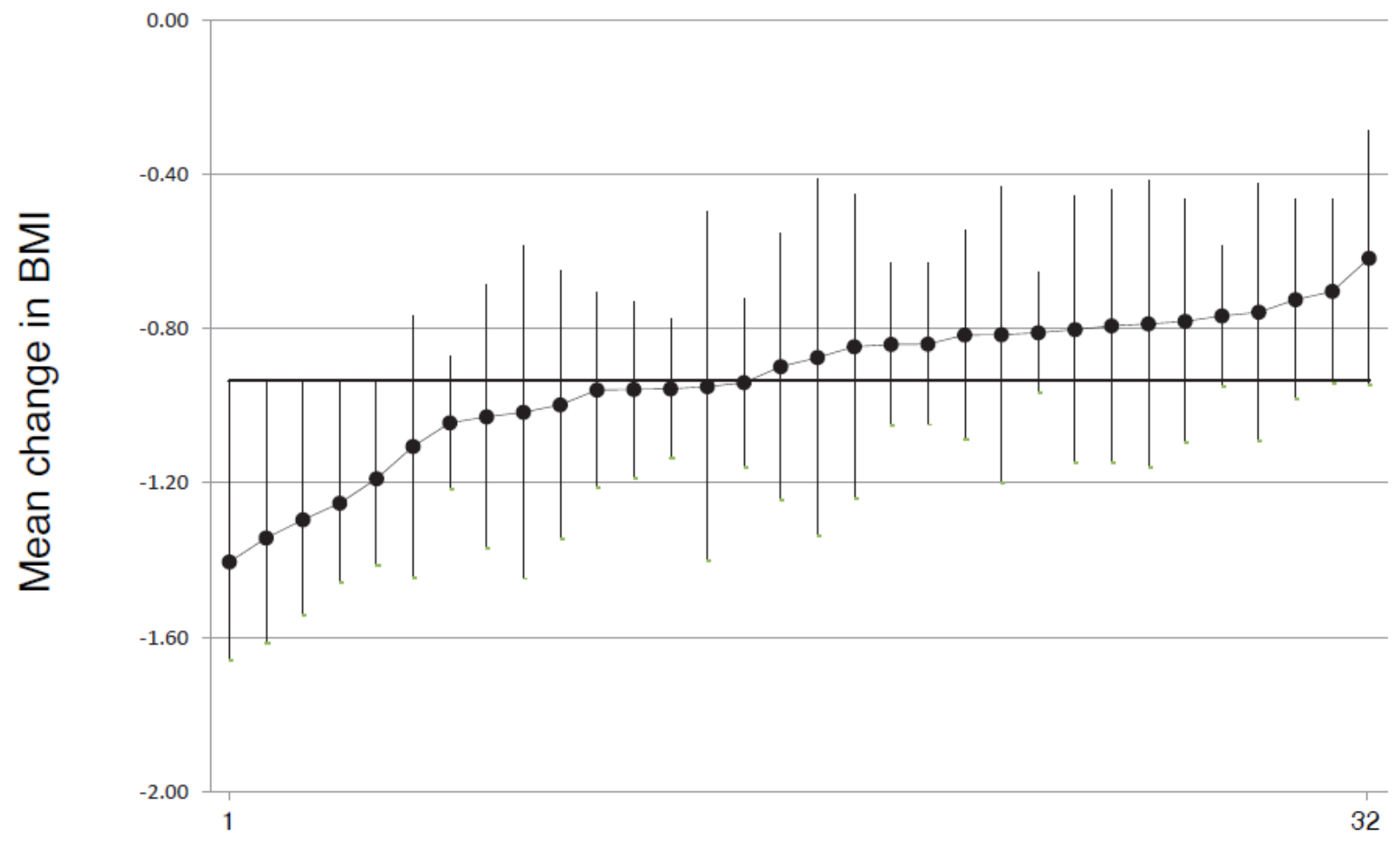

Dietitian 